\title{
Commentary Ocular sonography in patients with raised intracranial pressure: the papilloedema revisited
}

\author{
Thomas Geeraerts ${ }^{1,2}$, Jacques Duranteau ${ }^{2}$ and Dan Benhamou ${ }^{2}$
}

\begin{abstract}
1 University Department of Anaesthesia, Addenbrooke's Hospital and University of Cambridge, Cambridge CB2 2QQ, UK
${ }^{2}$ AP-HP, Univ Paris-Sud, Hôpital Bicêtre, Département d'Anesthésie-Réanimation, F-94275 Le Kremlin-Bicêtre, France
\end{abstract}

Corresponding author: Dr Thomas Geeraerts, thgeeraerts@hotmail.com

Published: 16 May 2008

Critical Care 2008, 12:150 (doi:10.1186/cc6893)

This article is online at http://ccforum.com/content/12/3/150

(c) 2008 BioMed Central Ltd

See related research by Soldatos et al., http://ccforum.com/content/12/3/R67

\begin{abstract}
Invasive devices are recommended for the early detection of raised intracranial pressure (ICP) after severe traumatic brain injury. Owing to contraindication or local issues, however, invasive ICP monitoring is not always possible. Moreover, a significant proportion of moderate traumatic brain injury patients (managed without invasive ICP) will develop raised ICP. Reliable noninvasive ICP techniques are therefore needed. Soldatos and colleagues report the usefulness of ocular sonography in the diagnosis of raised ICP. Focusing on cerebrospinal fluid accumulation around the retrobulbar optic nerve, they show interesting results for the optic nerve sheath diameter in the diagnosis of raised ICP. If confirmed by further studies, and despite important limitations related to sonography, this technique could serve as a screening test in patients at risk for raised ICP, when invasive monitoring is not possible or is not clearly recommended.
\end{abstract}

In the present issue of Critical Care, Soldatos and colleagues present a clinical study investigating the relationship between the optic nerve sheath diameter (ONSD), measured using ocular sonography, and the intracranial pressure (ICP) [1]. In 32 severe traumatic brain injury patients, a positive relationship was observed between the ONSD and invasive ICP $(r=0.68)$. Correlations between the ONSD and other noninvasive assessments of ICP (transcranial Doppler and Marshall's classification for head computed tomography scan) were also investigated with very similar results. Using a receiver operating characteristic curve, the best ONSD cutoff value was documented $(5.7 \mathrm{~mm})$ with good performance for the prediction of raised ICP. This noninvasive, bedside evaluation of ICP appears very attractive for clinical use, and the authors should be congratulated for this well conducted study.

The optic nerve, as a part of the central nervous system, is surrounded by a dural sheath that is distensible in its retrobulbar segment. In the case of raised pressure in the cerebro- spinal fluid, the retrobulbar optic nerve sheath can therefore inflate. More than 40 years ago, Hayreh showed in an elegant experimental study in monkeys and humans that subarachnoid spaces surrounding the optic nerve communicate with the intracranial cavity, and that cerebrospinal fluid pressure changes can be transmitted along the optic nerve sheath [2]. Interestingly, fundus changes (oedema of the optic disk) started several days after the beginning of raised ICP, making it not clinically pertinent for early detection of raised ICP.

Ocular sonography is extensively and safely used for ophthalmic evaluation after more than 20 years without specific contraindication except for wounds of the ocular globe [3]. Multipurpose ultrasound units with high-frequency transducers $(>7.5 \mathrm{MHz})$, now available in most intensive care unit ultrasound systems, have high lateral and axial precision [4].

There is a growing body of evidence in the clinical setting suggesting that millimetric increases in the sonographic ONSD are related to raised ICP. During a lumbar intrathecal infusion test, ONSD dilation reaches a maximum at peak cerebrospinal fluid pressure [5]. High ONSD values have been observed in children with clinical signs of high ICP during hydrocephalus or hepatic failure $[6,7]$. In adults with moderate traumatic brain injury, the ONSD correlates with signs of high ICP on computed tomography scan $[8,9]$. Before Soldatos and colleagues' paper, however, only one clinical study had compared sonographic ONSD with invasive ICP, which remains the gold standard [10]. Interestingly, these two studies, both performed in the intensive care unit setting, have found a similar best cutoff value for the ONSD to diagnose raised ICP $(5.7 \mathrm{~mm})[1,10]$.

There are some obvious limitations to the use of ocular sonography in the detection of raised ICP. Sonography allows only

$\mathrm{ICP}=$ intracranial pressure; ONSD = optic nerve sheath diameter. 
sequential measures while ICP is a dynamic parameter that can change very rapidly. Significant episodes of raised ICP can therefore remain unrecognised by sonographic examination. ICP prediction remains difficult with sonography as an ICP range $>10 \mathrm{mmHg}$ can be observed for an ONSD value. Despite these limitations, however, performances of this test to diagnose raised ICP appear interesting in a clinical decision-making approach. As shown by the receiver operating characteristic curve, higher sensitivity for raised ICP could probably be achieved with a lower cutoff value of the ONSD, making this tool attractive to rule out raised ICP. Nevertheless, larger studies are needed to be precise and to confirm the accuracy of this method. The effect of an acute change in ICP and the time reaction for ONSD enlargement or deflation should also be studied. Finally, the real-life feasibility and accuracy of ocular sonography, performed by nonexperienced physicians, are also key points to address in future studies.

Guidelines for traumatic brain injury management recommend measuring and monitoring continuously the ICP using an invasive device [11]. It is essential to remember that strategies based only on noninvasive measurement of ICP cannot be recommended today. At hospital admission, however, the early identification of severely brain-injured patients is critical to initiate prompt therapy. In this period, during focused assessment with sonography for trauma and before invasive ICP can be obtained, noninvasive assessment of cerebral blood flow using transcranial Doppler has been shown to help for patient triage and therapy [12]. In the same way, ocular sonography integrated into a future focused assessment with sonography for trauma could possibly add important additional information on intracranial pressure.

Raised ICP is not a rare occurrence during liver failure, acute ischaemic stroke, cerebral venous thrombosis, meningitis or encephalitis [13-15]. These patients are usually managed without invasive ICP monitoring. The worst attitude would be to ignore the danger of raised ICP and to take an unacceptable risk of cerebral ischemia. Here again, ocular sonography could be of interest for the early detection of raised ICP, and perhaps for the decision to initiate a more aggressive monitoring strategy.

In summary, Soldatos and colleagues provide encouraging results for the use of ocular sonography in the detection of raised ICP. This method should obviously not replace invasive ICP, which allows guided-directed therapy by giving continuous and reliable information. The present study, however, adds arguments to develop ONSD measurement when raised ICP is suspected but when invasive ICP monitoring cannot be used or is not clearly recommended. More than 40 years after Hayreh's study [2], translating research from the bench to the intensive care unit bedside has come a very long way. Ocular sonography certainly needs more validation, but today the old papilloedema sign is revisited with the help of modern ultrasound focusing on cerebrospinal fluid accumulation around the retrobulbar optic nerve.

\section{Competing interests}

The authors declare that they have no competing interests.

\section{Acknowledgements}

TG is supported by grants from the Société Française d'Anesthésie et de Réanimation and from Journées d'Enseignement Post-Universitaire d'Anesthésie-Réanimation - Novo Nordisk.

\section{References}

1. Soldatos T, Karakitsos D, Chatzimichail K, Papathanasiou M, Gouliamos A, Karabanis A: Optic nerve sonography in the diagnosis evaluation of adult brain injury. Crit Care 2008, 12:R67.

2. Hayreh SS: Pathogenesis of oedema of the optic disk (papilloedema), a preliminary report. Br J Ophthal 1964, 48:522-543.

3. Munk PL, Vellet AD, Levin M, Lin DT, Collyer RT: Sonography of the eye. Am J Roentgenol 1991, 157:1079-1086.

4. Berges O, Koskas P, Lafitte F, Piekarski JD: Sonography of the eye and orbit with a multipurpose ultrasound unit. $J$ Radiol 2006, 87(4 Pt 1):345-353.

5. Hansen HC, Helmke K: Validation of the optic nerve sheath response to changing cerebrospinal fluid pressure: ultrasound findings during intrathecal infusion tests. J Neurosurg 1997, 87:34-40.

6. Helmke K, Burdelski M, Hansen HC: Detection and monitoring of intracranial pressure dysregulation in liver failure by ultrasound. Transplantation 2000, 70:392-395.

7. Newman WD, Hollman AS, Dutton GN, Carachi R: Measurement of optic nerve sheath diameter by ultrasound: a means of detecting acute raised intracranial pressure in hydrocephalus. Br J Ophthalmol 2002, 86:1109-1113.

8. Blaivas $M$, Theodoro D, Sierzenski PR: Elevated intracranial pressure detected by bedside emergency ultrasonography of the optic nerve sheath. Acad Emerg Med 2003, 10:376-381.

9. Tayal VS, Neulander M, Norton HJ, Foster T, Saunders T, Blaivas $\mathrm{M}$ : Emergency department sonographic measurement of optic nerve sheath diameter to detect findings of increased intracranial pressure in adult head injury patients. Ann Emerg Med 2007, 49:508-514.

10. Geeraerts T, Launey Y, Martin L, Pottecher J, Vigue B, Duranteau J, Benhamou D: Ultrasonography of the optic nerve sheath may be useful for detecting raised intracranial pressure after severe brain injury. Intensive Care Med 2007, 33:1704-1711.

11. Brain Trauma Foundation: Guidelines for the management of severe traumatic brain injury. J Neurotrauma 2007, 24(Suppl 1):S37-S44.

12. Ract C, Le Moigno S, Bruder N, Vigue B: Transcranial Doppler ultrasound goal-directed therapy for the early management of severe traumatic brain injury. Intensive Care Med 2007, 33: 645-651.

13. Ware AJ, D'Agostino AN, Combes B: Cerebral edema: a major complication of massive hepatic necrosis. Gastroenterology 1971, 61:877-884.

14. Newton CR, Crawley J, Sowumni A, Waruiru C, Mwangi I, English M, Murphy S, Winstanley PA, Marsh K, Kirkham FJ: Intracranial hypertension in Africans with cerebral malaria. Arch Dis Child 1997, 76:219-226.

15. Vahedi K, Hofmeijer J, Juettler E, Vicaut E, George B, Algra A, Amelink GK, Schmiedeck P, Schwab S, Rothwell PM, Bousser MG, van der Worp HB, Kacke W: Early decompressive surgery in malignant infarction of the middlle cerebral artery: a pooled analysis of three randomised controlled trials. Lancet Neurol 2007, 6:215-222. 